Pacific Journal of Mathematics

SOME THREE-POINT SUBSET PROPERTIES CONNECTED
WITH MENGER'S CHARACTERIZATION OF BOUNDARIES O
PLANE CONVEX SETS

PLANE CONVEX 


\title{
SOME THREE-POINT SUBSET PROPERTIES CONNECTED WITH MENGER'S CHARACTERIZATION OF BOUNDARIES OF PLANE CONVEX SETS
}

\author{
KARSTEN JUUL
}

\begin{abstract}
An elementary characterization of those plane sets which are boundaries of convex sets is given together with other results of the same character.
\end{abstract}

1. Introduction. A theorem of K. Menger [1], see also F. A. Valentine [3], states that a plane compact set $S$ is the boundary of some (bounded) convex set if and only if $S$ satisfies certain simple conditions expressible in terms of the three-point subsets of $S$. The main result of the present note is an extension of Menger's theorem to possibly unbounded closed sets (Theorem 3). We shall start by studying subsets of boundaries of convex sets, the main tool being one of Menger's conditions. Our final result (Theorem 4) is an extension of a theorem of Valentine [3], giving a description of those sets satisfying another of Menger's conditions. The results of this note may be related to an unpublished work of W. M. Swan [2].

The assertion of Theorem 3 is illustrated in the figure: A closed set $S$ containing three noncollinear points is the boundary of a convex set if and only if, for any noncollinear points $x, y, z \in S$, firstiy, each of the six closed areas with strong hatching (the dotted lines are medians in triangle $x y z$ ) contains points from $S$ other than $x, y, z$, and secondly, the interior of triangle $x y z$ contains no points from $S$. Instead of the second condition we might have required that the interior of each of the three weakly hatched angles contained no points from $S$.

2. Terminology. Everything takes place in the plane. The interior, boundary, and convex hull of a set $S$ are denoted by int $S$, bd $S$, and conv $S$, respectively. The closed and open segments with endpoints $x$ and $y$ are denoted by $[x, y]$ and $] x, y$ [, respectively. If $x, y, z$ are noncollinear points, $L(x, y)$ and $H(x, y ; z)$ denote the line through $x$ and $y$, and the closed half-plane $H$ with $x, y \in$ bd $H, z \in H$, respectively. A convex curve is a connected subset of the boundary of a convex set. 


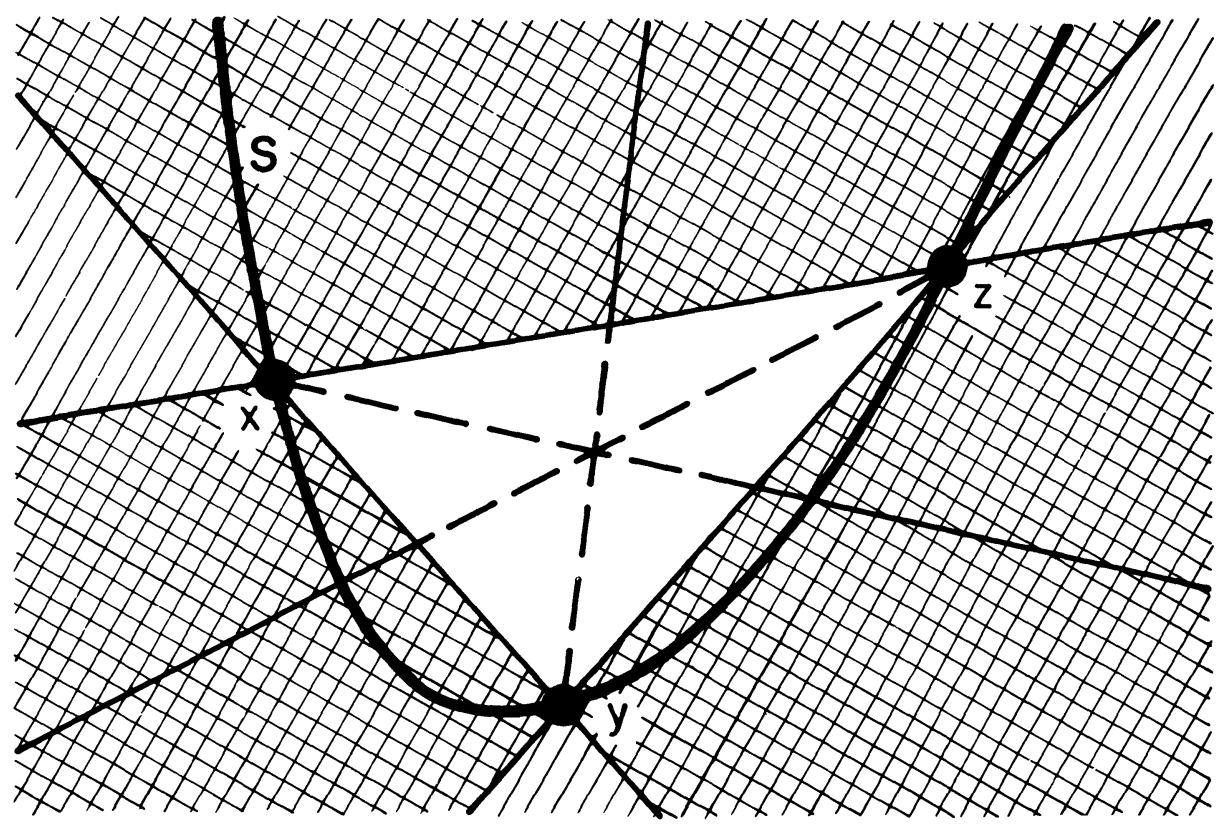

\section{Results and proofs.}

Proposition. A plane set $S$ fulfils

$$
\forall x, y, z \in S: S \cap \text { int } \operatorname{conv}\{x, y, z\}=\varnothing
$$

if and only if $S$ is either a subset of the boundary of a convex set, or an $X$-set, that is a set $\left\{x_{1}, x_{2}, x_{3}, x_{4}, x_{5}\right\}$ with $] x_{1}, x_{2}[\cap] x_{3}, x_{4}\left[=\left\{x_{5}\right\}\right.$.

Proof. The "if" statement is obvious. To prove the "only if" statement, assume (§) and $S \not \subset$ bd conv $S$. There are noncollinear $p, w, x \in S$ with $p \in$ int conv $S$. Let $V$ denote the complement of $H(p, x ; w) \cup H(p, w ; x)$. Then $S \cap V=\varnothing$ by (§). Since $p \in$ int conv $S$, there is an open half-plane $H$ with $p \in$ bd $H, V \subseteq H$ such that there are $y, z \in S \cap H$ with $y \in H(p, w ; x), z \in H(p, x ; w)$. By (§) we see that $p \in] x, z[, p \in] w, y[$ and that $S$ cannot contain more points than $p, w, x, y, z$. Thus $S$ is an $X$-set.

THEOREM 1. A connected set $S$ is a convex curve if and only if ( $($ ).

Proof. Since an $X$-set is not connected, the assertion follows by the proposition. 


\section{THEOREM 2. A connected set $S$ is a convex curve if}

$$
\forall x, y \in S: S \cap] x, y[=\varnothing \text {. }
$$

Proof. Suppose $S$ is a connected set fulfilling $\left(\S^{\prime}\right)$, but not being a convex curve. By Theorem 1 there are $w, x, y, z \in S$ with $w \in$ int conv $\{x, y, z\}$. Let the points $r$ and $t$ be determined by $r \in[x, y]$, $w \in[r, z]$ and $t \in[y, z], w \in[x, t]$, respectively, and the point $u$ by $u \in[y, w] \cap[r, t] . \quad$ By $\left(\S^{\prime}\right), S \cap L(w, z)=\{w, z\}, S \cap L(x, w)=\{x, w\}$, and $u \notin S$. Since $S$ is connected, either $] u, r[$ or ] $u, t$ [, say ] $u, r$ [, contains a point $p \in S$. By $\left(\S^{\prime}\right), S \cap L(y, p)=\{y, p\}$, hence $x$ and $w$ are not in the same component of $S$, a contradiction.

THEOREM 3. A closed set $S$ containing three noncollinear points is the boundary of a convex set if and only if (\$) and

$$
\forall x, y, z \in S: S \cap \sqrt{ }(x, y, z) \neq \varnothing,
$$

where we define $\sqrt{ }(x, y, z)$ to be the whole plane if $x, y, z$ are collinear, and otherwise, letting $V$ denote the closed convex cone with vertex $y$ whose boundary contains $z$ and the midpoint $x \oplus z$ of $[x, z]$, to be $V$ deprived of $z$ and the part contained in the open half-plane I with $x, z \in$ bd $I$ and $y \in I$.

Proof. First we shall prove the "only if" statement. Suppose $S=$ bd $C$ where $C$ is a closed convex set. Then $(\S)$ is obvious. To prove $(*)$, let $x, y, z \in S$ be noncollinear. Letting $V$ denote the complement of $H(x, z ; y) \cup H(y, z ; x)$, we have $C \cap V=\varnothing$. Let $r \in V$. Now $x \oplus z \in C$ and $r \notin C$ so $S \cap[x \oplus z, r] \neq \varnothing$, whence $S \cap$ $\sqrt{ }(x, y, z) \neq \varnothing$.

Next we shall prove the "if" statement. Observing that $(*)$ implies that $S$ is not an $X$-set and using ( $($ ) we get $S \subseteq$ bd conv $S$ by Proposition 2. Assume $a \in($ bd conv $S) \backslash S$.

Let $H$ be a closed half-plane with $a \in$ bd $H, S \subseteq H$. There is a point in $S \cap$ bd $H$, and hence a point $x \in$ bd $H$ fulfilling $S \cap[x, a]=\{x\}$, for assume $S \cap$ bd $H=\varnothing$, and let $\left(x_{n}\right)$ be a sequence in $S$ such that the distance from $x_{n+1}$ to $H$ is less than half of the distance from $x_{n}$ to $H$. We may assume that all the $x_{n}, n \geqq 2$ are in the same open half-plane $K$ with $x_{1}, a \in$ bd $K$. In addition, consider a half-plane $N$ with $x_{2} \in$ bd $N, S \subseteq N$. Then it is seen that $\left(x_{n}\right)$ has an accumulationpoint lying in bd $H$, a contradiction.

There are $y, z \in S$ such that $y \in$ int $H, z \notin H(x, y ; a)$, for the assumption $v \in S, a \in$ ] $x, v$ [ would contradict (*). Choose $p \in S \cap$ $\sqrt{ }(z, x, y)$ and let $M$ denote the closed half-plane with $x \oplus y \in b d M$, 
$M \subseteq H$. Now $\quad p \in M \cap$ int $H(x, y ; z)$ since $S \cap L(x, y)=\{x, y\}$. Choose $q \in S \cap \sqrt{ }(y, p, x)$, then $q \in H \backslash \operatorname{int}(H(y, a ; x) \cup M)$.

Consider a closed half-plane $R$ with $q \in$ bd $R, S \subseteq R$, and consider all the half-planes $T$ such that $a \in T$ and bd $T$ cuts ] $q, a$ [ and ]$x, a[$. Since all the $T$ contain points from $S$, there is a point $u \in S$ with $a \in] x, u[$, a contradiction.

THEOREM 4. For a connected set $S$ such that

$(* *)$

$$
\forall x, y, z \in S: y \in] x, z[\Rightarrow[x, z] \subseteq S,
$$

at least one of the following four conditions holds:

(1) int $S$ is convex and $S \subseteq$ cl int $S$.

(2) $S$ is a convex curve.

(3) $S$ is the union of two non-disjoint linear elements, a linear element being a connected subset of a line.

(4) $S$ is the union of three linear elements $P, Q, R$ with a common endpoint contained in $S$ and int conv $(P \cup Q \cup R)$.

Proof. Suppose $S$ is a connected set fulfilling (**), but none of the four conditions.

We have int $S=\varnothing$ since otherwise (1) were true.

By Theorem 1 and non(2) there are points $a, b, c, d \in S$ with $d \in$ int conv $\{a, b, c\}$. An argument resembling the one in Theorem 2 shows that one of the segments $[a, d],[b, d]$, and $[c, d]$, say $[a, d]$, is part of $S$.

Put $R=S \cap L(a, d)$ and let $i$ be the point determined by $i \in$ $L(a, d) \cap[b, c]$. Now $i \notin S$, for otherwise $S \cap(L(a, d) \cup L(b, c))$ fulfils (3) so $S \backslash(L(a, d) \cup L(b, c)) \neq \varnothing$, whence int $S \neq \varnothing$, a contradiction. By a similar argument we see that for a point $m$, $R \cap] m, b[\neq \varnothing$ implies $m \notin S$. Hence, letting $n$ denote the endpoint of $R$ nearest to $i$, there is an open half-line $T$ with endpoint $n$ and $S \cap T=\varnothing$ such that $T$ together with $L(a, d) \backslash R$ and $\{n\}$ separates $c$ from $R$. Thus $n \in S$. By non(4), $S$ cannot contain both $[b, n]$ and $[c, n]$, hence we may assume $S \cap L(b, n)=\{b, n\}$.

Let $j \in R \backslash\{n\}$ and let the points $k$ and $l$ be determined by $k \in[j, b] \cap L(n, c)$ and $l \in[k, i] \cap[n, b]$, respectively. By non(3) we get $S \cap L(c, n)=\{c, n\}$ and $S \cap] k, l[=\varnothing$. Moreover $S \cap] l, i[$ is empty, for if it contained a point $p$, then, since $S \cap] n, i[=\varnothing,(* *)$ would imply that $S$ had no point in $L(p, b) \cap H(n, i ; c)$ contradicting that $S$ is a connected set containing $b$ and $c$. But then we have a new contradiction to the connectedness of $S$, and the proof is complete. 


\section{REFERENCES}

1. K. Menger, Some applications of point set methods, Ann. Math., 32 (1931), 739-750.

2. W. M. Swan, A generalization of a theorem of Menger, Master's Thesis, U.C.L.A. (1954).

3. F. A. Valentine, Convex sets, McGraw-Hill (New York, 1964).

Received September 3, 1974.

KARSTEN JUUL

HøJAGERPARKEN 41, 2. SAL

2750 BALLERUP

DENMARK 



\section{PACIFIC JOURNAL OF MATHEMATICS}

\section{EDITORS}

RICHARD ARENS (Managing Editor)

University of California

Los Angeles, California 90024

\section{J. DugundJI}

Department of Mathematics University of Southern California Los Angeles, California 90007

D. Gilbarg and J. Milgram

Stanford University

Stanford, California 94305

\section{ASSOCIATE EDITORS}
E. F. BECKENBACH
B. H. NeumanN
F. WoLF
K. YoshiDA

\section{SUPPORTING INSTITUTIONS}

\author{
UNIVERSITY OF BRITISH COLUMBIA \\ CALIFORNIA INSTITUTE OF TECHNOLOGY \\ UNIVERSITY OF CALIFORNIA \\ MONTANA STATE UNIVERSITY \\ UNIVERSITY OF NEVADA \\ NEW MEXICO STATE UNIVERSITY \\ OREGON STATE UNIVERSITY \\ UNIVERSITY OF OREGON \\ OSAKA UNIVERSITY
}

\author{
UNIVERSITY OF SOUTHERN CALIFORNIA \\ STANFORD UNIVERSITY \\ UNIVERSITY OF TOKYO \\ UNIVERSITY OF UTAH \\ WASHINGTON STATE UNIVERSITY \\ UNIVERSITY OF WASHINGTON \\ AMERICAN MATHEMATICAL SOCIETY
}

The Supporting Institutions listed above contribute to the cost of publication of this Journal, but they are not owners or publishers and have no responsibility for its contents or policies.

Mathematical papers intended for publication in the Pacific Journal of Mathematics should be in typed form or offset-reproduced (not dittoed), double spaced with large margins. Underline Greek letters in red, German in green, and script in blue. The first paragraph or two must be capable of being used separately as a synopsis of the entire paper. Items of the bibliography should not be cited there unless absolutely necessary, in which case they must be identified by author and Journal, rather than by item number. Manuscripts, in duplicate, may be sent to any one of the four editors. Please classify according to the scheme of Math. Reviews, Index to Vol. 39. All other communications should be addressed to the managing editor, or Elaine Barth, University of California, Los Angeles, California, 90024.

100 reprints are provided free for each article, only if page charges have been substantially paid. Additional copies may be obtained at cost in multiples of 50 .

The Pacific Journal of Mathematics is issued monthly as of January 1966. Regular subscription rate: $\$ 72.00$ a year (6 Vols., 12 issues). Special rate: $\$ 36.00$ a year to individual members of supporting institutions.

Subscriptions, orders for back numbers, and changes of address should be sent to Pacific Journal of Mathematics, 103 Highland Boulevard, Berkeley, California, 94708.

PUBLISHED BY PACIFIC JOURNAL OF MATHEMATICS, A NON-PROFIT CORPORATION Printed at Jerusalem Academic Press, POB 2390, Jerusalem, Israel.

$$
\begin{gathered}
\text { Copyright (C) } 1975 \text { Pacific Journal of Mathematics } \\
\text { All Rights Reserved }
\end{gathered}
$$




\section{Pacific Journal of Mathematics}

\section{Vol. 58, No. $2 \quad$ April, 1975}

Zvi Artstein and John Allen Burns, Integration of compact set-valued functions . . . . . . . . . 297

Mark Benard, Characters and Schur indices of the unitary reflection group $[321]^{3} \ldots \ldots \ldots . .309$

Simeon M. Berman, A new characterization of characteristic functions of absolutely continuous

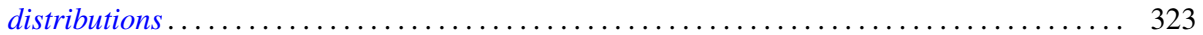

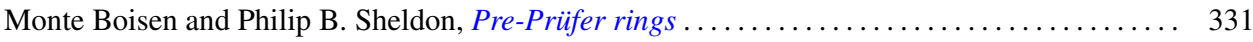

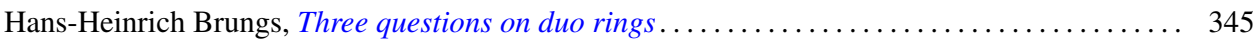

Iracema M. Bund, Birnbaum-Orlicz spaces of functions on groups................. 351

John D. Elwin and Donald R. Short, Branched immersions between 2-manifolds of higher

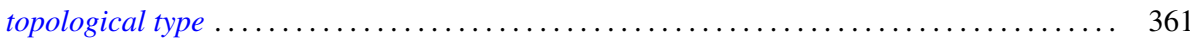

Eric Friedlander, Extension functions for rank 2, torsion free abelian groups . .......... 371

Jon Froemke and Robert Willis Quackenbush, The spectrum of an equational class of

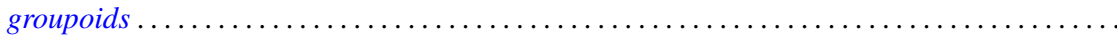

Barry J. Gardner, Radicals of supplementary semilattice sums of associative rings ...........

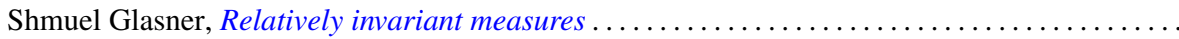

George Rudolph Gordh, Jr. and Sibe Mardesic, Characterizing local connectedness in inverse

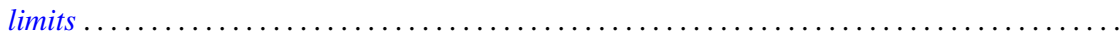

Siegfried Graf, On the existence of strong liftings in second countable topological spaces......

Stanley P. Gudder and D. Strawther, Orthogonally additive and orthogonally increasing

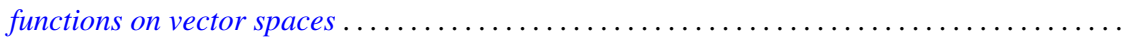

Darald Joe Hartfiel and Carlton James Maxson, A characterization of the maximal monoids and

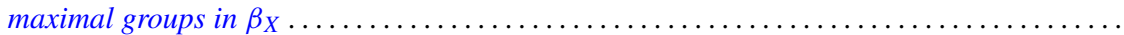

Robert E. Hartwig and S. Brent Morris, The universal flip matrix and the generalized faro-shuffle. .

William Emery Haver, Mappings between ANRs that are fine homotopy equivalences. .

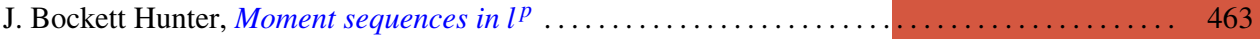

Barbara Jeffcott and William Thomas Spears, Semimodularity in the completion of a poset.... 467

Jerry Alan Johnson, A note on Banach spaces of Lipschitz functions . . . . . . . . . . . . 475

David W. Jonah and Bertram Manuel Schreiber, Transitive affine transformations on

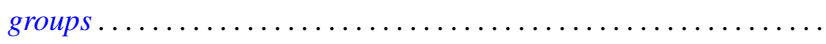

Karsten Juul, Some three-point subset properties connected with Menger's characterization of

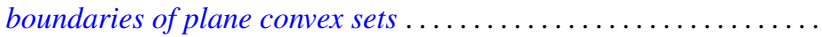

Ronald Brian Kirk, The Haar integral via non-standard analysis . . . . . . . . . . . . . 517

Justin Thomas Lloyd and William Smiley, On the group of permutations with countable

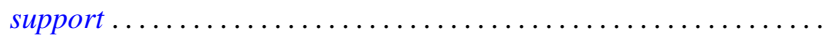

Erwin Lutwak, Dual mixed volumes .................................. 531

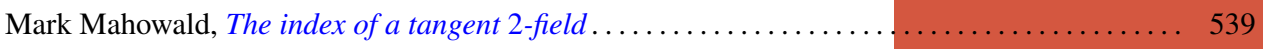

Keith Miller, Logarithmic convexity results for holomorphic semigroups . . . . . . . . . . . . 549

Paul Milnes, Extension of continuous functions on topological semigroups . . . . . . . . . . 553

Kenneth Clayton Pietz, Cauchy transforms and characteristic functions ................ 563

James Ted Rogers Jr., Whitney continua in the hyperspace $C(X) \ldots \ldots \ldots \ldots \ldots \ldots \ldots \ldots .569$

Jean-Marie G. Rolin, The inverse of a continuous additive functional . . . . . . . . . . . . 585

William Henry Ruckle, Absolutely divergent series and isomorphism of subspaces . ........ 605

Rolf Schneider, A measure of convexity for compact sets . ..................... 617

Alan Henry Schoenfeld, Continous measure-preserving maps onto Peano spaces .......... 627

V. Merriline Smith, Strongly superficial elements .......................... 643

Roger P. Ware, A note on quadratic forms over Pythagorean fields . . . . . . . . . . . . . . 651

Roger Allen Wiegand and Sylvia Wiegand, Finitely generated modules over Bezout rings . . . . 655

Martin Ziegler, A counterexample in the theory of definable automorphisms . . . . . . . . . 665 